\title{
CORPO-EM-ARTE: PERFORMANCE
}

\author{
ATILIO CATOSSO SALLES*
}

\begin{abstract}
RESUMO: Esta pesquisa, filiada ao domínio teórico da escola francesa da Análise de Discurso, tem interesse em investigar a articulação sujeito/corpo/arte. Para tanto, o corpus discursivo é constituído de uma performance intitulada "The artist is present", produzida pela artista Marina Abramovic, no MoMa, em 2010. Interessa, pois, pensar como se dá o trabalho de compreensão de uma performance, perguntando pelos sentidos que tomam corpo e tomam $O$ corpo do sujeito. Nas discursividades analisadas, o movimento dos sentidos, do sujeito com o seu olhar e o seu corpo, em um território (espaço-histórico-social), determina sentidos possíveis, em posições discursivas possíveis, funcionando como espessura material significante. Uma espessura material que é estrutural, simbólica e formulada como linguagem.

Palavras-chave: Quadro cênico; corpo; sujeito; performance.
\end{abstract}

ABSTRACT: This research, affiliated to the theoretical domain of the French School of Discourse Analysis, is interested in investigating the subject / body / art articulation. For that, the discursive corpus consists of a performance titled "The artist is present", produced by the artist Marina Abramovic, in MoMa, in 2010. It is therefore interesting to think how the work of understanding a performance occurs, asking for the senses That take body and take the body of the subject. In the analyzed discourse, the movement of the senses, of the subject with its look and its body, in a territory (space-historicalsocial), determines possible senses, in possible discursive positions, functioning as significant material thickness. A material thickness that is structural, symbolic and formulated as language.

Keywords: Scenic frame; body; subject; peformance.

\section{INTRODUÇÃO}

Para efeito de um trabalho analítico/teórico em Análise de Discurso, invisto primeiro em pensar que "aos homens enquanto seres históricos e simbólicos que somos não nos basta falar para significar e nos significarmos" Orlandi (2001, p.154). De acordo com a autora, além de "falarmos", também, escrevemos poemas, cantamos, dançamos, fazemos literatura, cinema [...] entre outras diferentes formas de significação.

Nessa direção, estranhar os sentidos e os modos pelo quais o sujeito de diz e é dito é do que me ocupo aqui no início desta reflexão. De acordo com Orlandi

* Professor Adjunto do Programa de Pós-Graduação em Ciências da Linguagem da Universidade do Vale do Sapucaí. Esta pesquisa foi submetida à publicação durante meu estágio de Pós-Doutorado (CAPES/PNPD) realizado no Programa de Pós-Graduação em Ciências da Linguagem da Univás. atiliocs@gmail.com 
(2002) "o corpo do sujeito e corpo da linguagem não são transparentes". Sujeitos com/e seus corpos estão ligados ao corpo social (Orlandi, 2001), e isso também não é da ordem da transparência.

Meu interesse pelos processos de significação do sujeito com o seu corpo tomou forma com a pesquisa realizada sobre a cidade em minha dissertação de mestrado. Considerei, a partir da análise do documentário "Território Vermelho" (2004) do cineasta Kiko Koifman, o modo como o sujeito com o seu corpo atravessa o espaço público em uma faixa de pedestre. Um dos princípios desse meu trabalho, com a questão urbana, é que o corpo do sujeito vai se mostrando, sendo mostrado, atado ao corpo da cidade. Ele vai assim ganhando existência a partir dessa ligação com o espaço, com o que também está fora de seu corpo. Um modo do corpo (r)existir e assim se significar e, esse gesto de ocupar a faixa de pedestre (seja para atravessar, trabalhar, produzir arte) aponta, ao meu ver, para uma resistência que remete à questão da identificação no funcionamento próprio da ideologia que fal(h)a ao sujeito.

Este percurso no mestrado é constitutivo da minha relação com as questões de pesquisa (e, diria, de vida) que ora proponho compreender. Questões estas que giram, dançam, produzem volteios em torno da relação do sujeito, com seu corpo, em um espaço.

Articulando sujeito/corpo/linguagem, busco compreender como o corpo, recortado pela materialidade do sujeito, sua historicidade, se significa e produz significação em um espaço de existência; tomando os homens como seres simbólicos e históricos-sociais, pensando o interdiscurso e sua relação com o espaço. A esse respeito, Rolnik (2006) formula que nos significamos ao nos filiarmos a um território. Território aqui compreendido enquanto lugar de pertencimento pelo próprio de nossa existência, não como mero espaço físico com suas delimitações/divisas geográficas, mas sim espaço que também significa.

Finalmente, penso que a questão aqui é: qual a relação do corpo com a ideologia, como, em sua especificidade, em sua espessura material, o sujeito textualiza seu corpo (e se textualiza) pela maneira mesma como está nele (já) significado. O corpo normatizado, o corpo em movimento, o corpo fora de lugar, o corpo "instalado" de um sujeito que interpreta e é interpretação sem cessar.

Como material de pesquisa recorto uma performance intitulada "The artist is present", produzida pela artista Marina Abramovic, em 2010, no MoMa. Nessa performance, Marina Abramovi, no átrio do museu, em um espaço quadrado recortado por uma fita, dispõe uma mesa e duas cadeiras, sendo uma dessas cadeiras ocupada por ela, a outra ficou à disposição para as pessoas que estivessem visitando a exposição (organizada pelo MoMa para homenageá-la) pudessem se sentar e dividir um tempo indeterminado de silêncio com a artista. Assim se iniciou a performance.

M. Pêcheux (1990) considera que não só a língua, mas também a história tem seu real. A partir do texto "Processos de significação, corpo e sujeito", Orlandi (2012) propõe uma reflexão sobre o corpo, articulando as instâncias do inconsciente e da ideologia. De acordo com a autora: 
"Embora se trabalhe, na análise de discurso, sobejamente, a materialidade da história e da língua, pouco se tem dito a respeito da materialidade do sujeito, mesmo que se afirme sua não transparência, fazendo intervir a questão da ideologia e do inconsciente" (ORLANDI, 2012, p. 84).

Neste trabalho, proponho, tal como Orlandi (2001, 2002, 2012), tomar o corpo, o corpo de um sujeito, não enquanto um corpo empírico, constituído de carne. O que interessa é a materialidade do sujeito na relação do sujeito com o seu corpo, pois como afirma a autora, tratar da materialidade do corpo na relação com um sujeito é considerar a ideologia, a história e os processos de vida social intervindo sobre a produção da significação e é, nesse sentido, que se pode apontar que a relação do sujeito com o seu corpo aparece como transparente, mas não é.

Para introduzir, através dos elementos do discurso, o modo como estou compreendendo a performance, traço agora alguns apontamentos que considero importante investir sobre o trabalho do corpo e do olhar em/na arte.

A performance é uma arte de fronteira, podendo ser definida por alguns como uma arte híbrida. Já o termo performance act sugere eventos realizados por artistas, no bojo das 'experiências' vanguardistas europeias.

Richard Shechner (2003, p.39) propõe oito situações em que a linguagem artística pode se dar a ver:

1. na vida diária, cozinhando, socializando-se;

2. nas artes;

3. nos esportes e outros entretenimentos populares;

4. nos negócios;

5. na tecnologia;

6. no sexo;

7. nos rituais sagrados e seculares;

8. na brincadeira;

Tais situações empíricas em que a arte pode se dar a ver, num primeiro momento dessa reflexão, se colocam para mim como importantes, na medida mesma em que possibilitam jogar com a aproximação do corpo do artista, o público e a obra num só momento. E é nesse enlace do corpo numa relação forte com as artes, com o sexo, com a tecnologia... que corpo e sujeito - em relação $a$ - são convocados não mais para uma mera ou simples contemplação em performance.

É o corpo, o corpo em movimento que faz deslizar sentidos pelo espaço. Como é que durante esse processo de produzir uma performance é o próprio corpo que (se) produz - isto é, se torna isso ou aquilo que se percebeu - enquanto efeito no movimento de sua realização mesma? E, ainda, da realização do corpo em performance, o que fica para a arte que não seja só a marca da passagem de um corpo? E, em que lugar nós ficamos, os observadores, que afinal temos nosso próprio corpo?

Uma pista primeira para estas perguntas nos é oferecida por Phelan ao formular: "tentar escrever sobre o evento indocumentável da performance é 
invocar as regras do documento escrito e, logo, alterar o evento em si mesmo" (PHELAN, 1997, p.173).

E, nesse sentido, é consequente de minha posição tomar a arte não como um evento interpretável. A efemeridade da performance é a sua condição. Em movimento o que é registrado em uma performance não é a verdade, talvez o que se produza é um efeito de verdade. "A ação é verdade. Nada do que foi registrado é verdade. Nada do que foi dito é verdade. Somente a ação" (Jack Bowman, flyer distribuído no Cleveland Performance Art Festivall. Até porque nem é esse o esforço que anseio empreender. Mas sim considerar a performance como um recorte de um processo discursivo de significação que faz furo (ou não) no evento (nos termos de Badiou, 2013).

Ou, ainda, como melhor observa Orlandi sobre o papel da Análise de Discurso:

\begin{abstract}
...aquela que não explica, nem serve para tornar inteligível ou interpretar o sentido, mas que nos leva a melhor compreender os processos de significação, o modo de funcionamento de qualquer exemplar de linguagem para significar. Com efeito, a relação que a análise do discurso estabelece com o texto não é para dele extrair um sentido mas sim para problematizar essa relação, ou seja, para tornar visível sua historicidade e observar a relação de sentidos que aí se estabelece, em função do efeito de unidade. (2007, p. 173)
\end{abstract}

Para Pêcheux (1997: 161) “a expressão processo discursivo passará a designar o sistema de relações de substituições, paráfrases, sinonímias, etc., que funcionam entre elementos linguísticos - "significantes"- em uma formação discursiva dada." Desse modo, nesta pesquisa, proponho me voltar para a compreensão do(s) processo(s) de significação do objeto arte [dotado de discursividade] na relação com o trabalho da formulação, da constituição e da circulação (ORLANDI, 2001).

O objeto arte, observo, não está em somente um espaço de significação, este se formula na/pela sua re-significação, o que, por contraste, nos remete sempre a outros dizeres possíveis em jogo. Dito de outro modo, o sentido da matéria significante de nosso material está em seu lugar mesmo de inscrição, e, não apenas em seu constructo (constituição) físico ou formal (forma). Isso, pois, a matéria significante, costurada pelo social e histórico, produz efeitos de sentido, e não a matéria em si mesma. Orlandi (1999) ensina que "a linguagem é linguagem porque faz sentido. E a linguagem só faz sentido porque se inscreve na história". E é por essa via que penso a performance.

Sendo linguagem, a performance produz sentido(s). Pensando deste lugar, a performance é tomada, em sua imbricação material, como um complexo de significação envolto de dizeres contemporâneos que instala diferentes gestos de leitura determinados pela sua condição específica de produção, pondo em movimento o espaço da incompletude, da polissemia, do sentido outro possível. O movimento instala-se.

${ }^{1}$ No original: "The Act is TRUTH. Nothing that was ever recorded is truth. Nothing that was ever said is truth. Only the ACT". Cleveland Performance Art Festival. Disponível em: <http://www. performance-art.org>. Acesso em: 10 set. 2016. 
Tal tomada de posição discursiva colocou, desde o início, o conflituoso desafio de compreender o caráter material do corpo (e também do olhar) instalados - não de modo fixo, estático - na performance "The artist is present", mas sim no modo como esse corpo por uma dupla subordinação - de um lado a subordinação do corpo ao roteiro previsto formalmente na performance, subordinado à "regra" de ocupar um espaço determinado e de um modo determinado, e de outro lado o corpo investido da relação forte sujeito/ sentido/mundo produzindo a marca de uma passagem que faz furo na falha do ritual ideológico, possível lugar de resistência (PÊCHEUX, 2009). Ou seja, interessa-me ler as condições reais de produção e circulação, tendo como pedra de toque a noção de ideologia tal qual essa fora formulada por Pêcheux ${ }^{2}$ (2009).

Um adendo se faz importante neste percurso da pesquisa. Apesar de alguns pesquisadores elegerem um ou outro termo/expressão na análise da performance, jogando com palavras como Art charnel; Art corporel; Specimen art; Hardship art ou Ordeal arts, não proponho optar por um conceito ou outro aqui. No livro L'art corporel (1983), François Pluchart formulou: "Se a expressão 'arte corporal' tem o mérito de manter a questão do corpo no interior do domínio da arte, a palavra 'performance' gerou os piores mal-entendidos". Concordo com Pluchart, visto que em minha compreensão, o corpo é o próprio do sujeito e também o objeto da arte da performance. Eis um ponto de deslocamento.

A performance pode se dar na rua ou em espaço in situ. O quadro cênico da performance não se desenha ou se dá em um lugar específico senão em todos os que, à volta de nós, formam a cena. Pensemos na ideia de fluxo para pensarmos o espaço da performance; sendo fluxo, fluido, o espaço do quadro cênico pode se dar a ver em todos os espaços: espaço 'público', a rua, lá onde você caminha, lá onde paro para ler na praça, no espaço institucionalizado, em um museu, em uma galeria de arte, em uma escola. Nessa direção, compreendo que lugar, o lugar da performance, é o espaço praticado, espaço dotado de sentido.

\section{QUADRO CÊNICO: TERRITÓRIO, CARTOGRAFIA DOS SENTIDOS}

O sentido não é exato (ORLANDI, 2012). Em consequência da análise da arte performática também cabe dizer: o espaço recortado para a produção de uma performance também não é exato, é espaço praticado, é espaço político - ou seja, compreendido como divisão, em que ao mesmo tempo se abre para a estabilização e a desestabilização dos sentidos possíveis. Veremos isso na descrição que segue.

O Museu de Arte Moderna de Nova York, MoMa, foi fundado em 1929, foi o primeiro museu que dedicou sua coleção somente à arte moderna. Com um espaço aproximado de 60.000 metros quadrado, dividido em seis andares, o MoMa recebe todos os anos várias exposições artísticas de estilos variados como o expressionismo abstrato, arte metafísica, cubismo. Entre pinturas, esculturas,

${ }^{2}$ A primeira edição de "Les Vérités de La Palice" publicada em francês em 1975. Em 1988, a primeira tradução brasileira com o título "Semântica e Discurso. Uma crítica à afirmação do óbvio". Retomo neste trabalho uma edição recente publicada em 2009. 
instalações e fotografias o MoMa possui o maior o acervo de arte moderna do mundo.

Em 2010, Marina Abramoivic fora homenageada pelo MoMa com uma retrospectiva de sua carreira. Para esta exposição outros artistas foram convidados para reproduzir alguns dos trabalhos mais importantes de Abramovic. Em especial, para esta retrospectiva, a artista produziu a performance intitulada "The artist is present".

Ao longo da performance, com duração total de mais de 700 horas, Abramovic ficou em uma cadeira por oito horas diárias, seis vezes por semana, durante três meses, enquanto visitantes eram convidados a sentar-se de frente para ela, em silêncio e pelo tempo que desejassem. A artista apenas fechava os olhos cada vez que um visitante levantava e voltava a abri-los quando um outro ocupava o lugar.

Vejamos algumas imagens da performance:

Imagem 01:

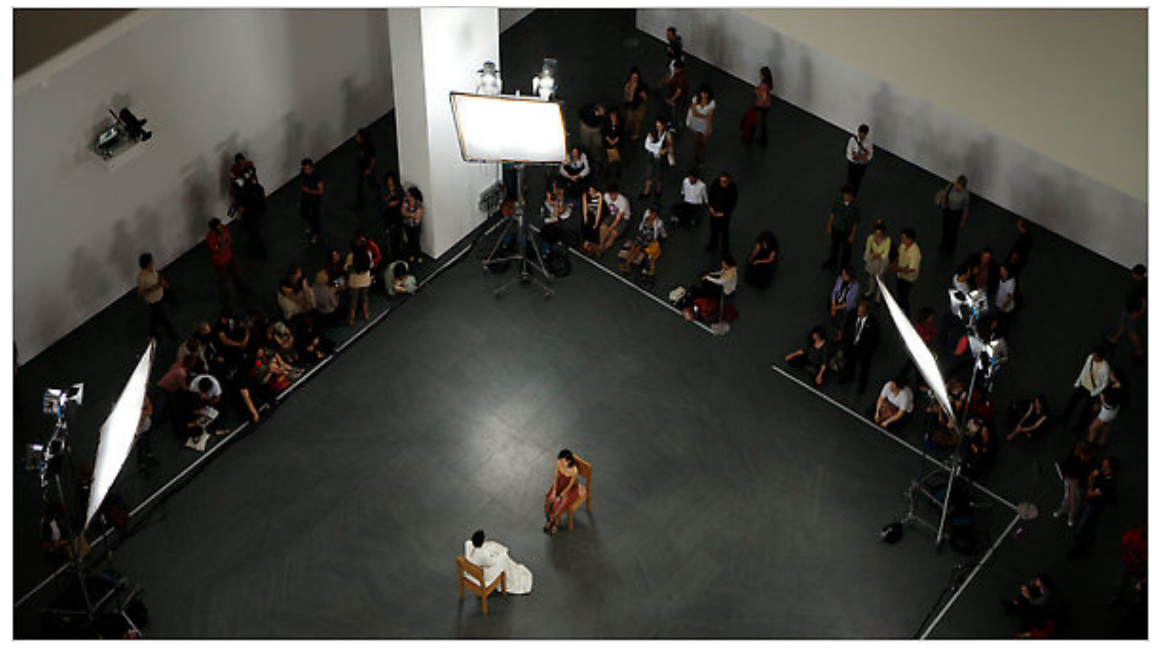


Imagem 02:

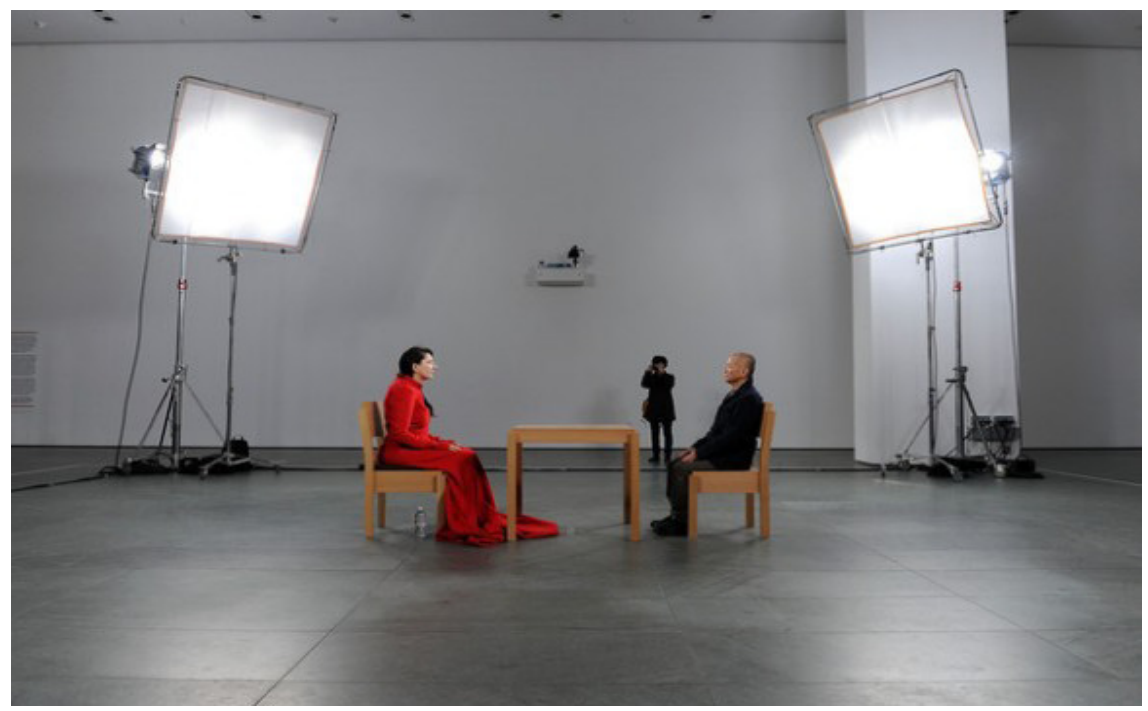

Imagem 03:

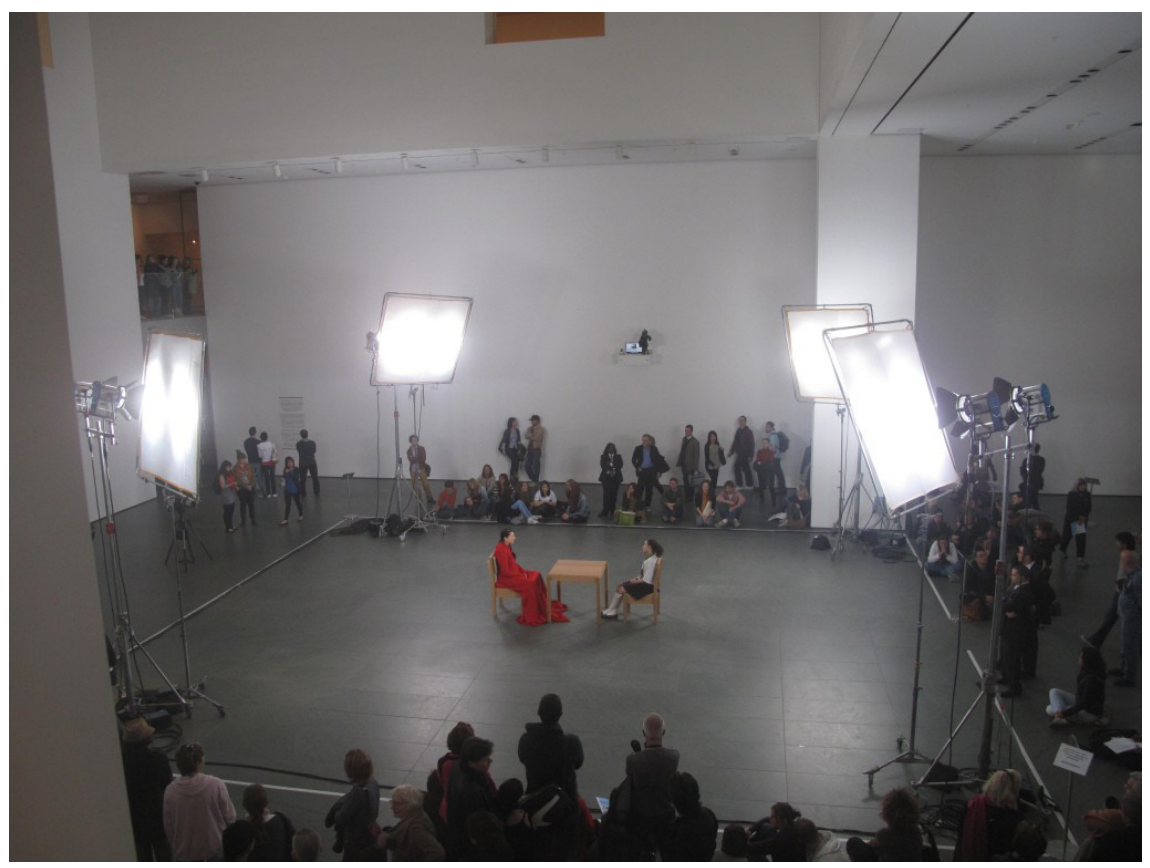




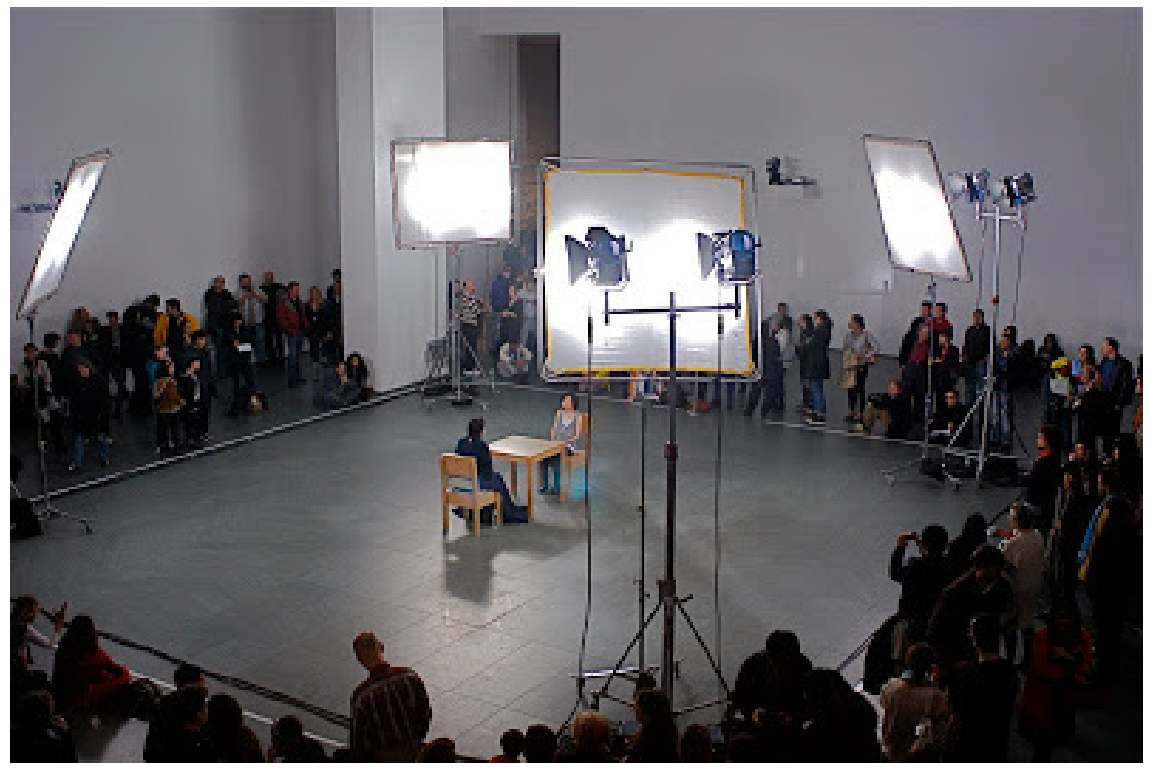

(Imagens do documentário “The artist is presente"(2010))

A partir desses recortes é possível observar o modo como é constituído o quadro cênico da performance. À primeira vista é um espaço simples, demasiadamente simples, em que a artista delimita. Um espaço quadrado no átrio do MoMa, recortado por uma faixa branca, iluminado por quatro refletores grandes, produzindo feixes de luz sobre duas cadeiras e uma mesa pequena que estão dispostas ao centro desse quadro cênico. $\mathrm{O}$ objetivo desse trabalho é desconstruir, reconstruir e, ao mesmo tempo, apontar para a produção de outros territórios de experimentação que se justapõem e se dobram uns sobre os outros e, nesse movimento, que se pode abrir potências de campos de significação, numa dobra de um espaço, agora re-significado. Não é mais o átrio do MoMa, é um território outro. Vejamos nesse esboço de mapa. 


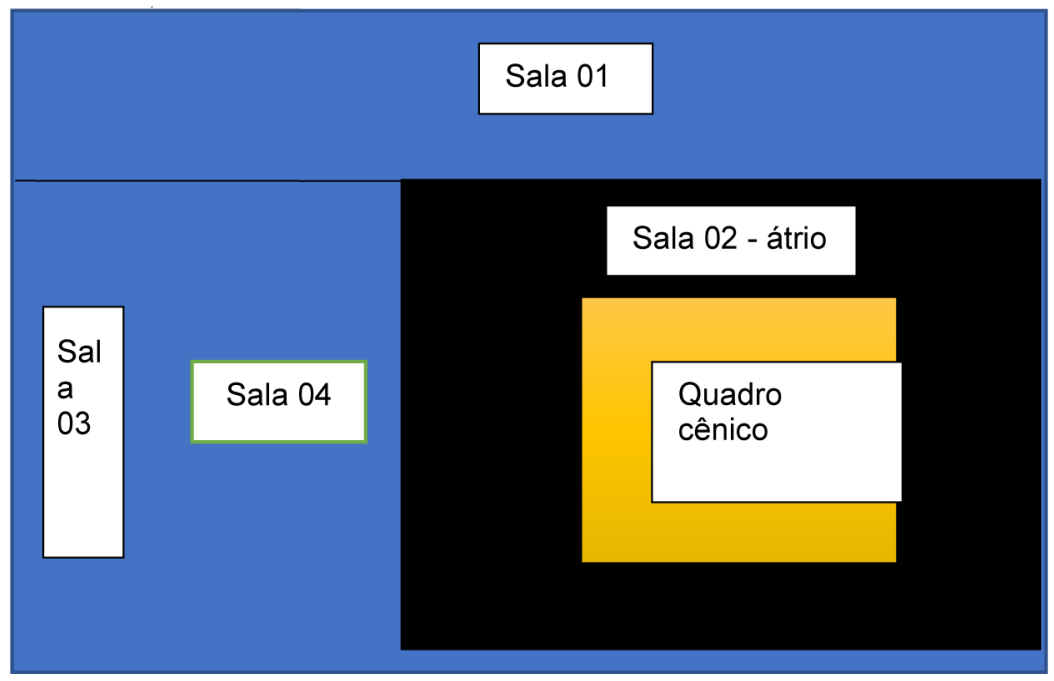

Ora, nessa passagem, se faz necessário evocar o que entendo por território. Como ponto de partida, território não é aqui um mero lugar topográfico, físico (conforme esboço acima), no qual a performance pode se dar a ver. A noção de território não vem primeiro, mas as ações performáticas que recortam tal território. Em nossa compreensão, território é campo constituído por uma intrincada rede de materialidades discursivas. São lugares que não pré-existem; o território é organizado, é traçado por um contorno de um centro incerto. Assim, os territórios se constituem ao mesmo tempo em que são produzidos, formas materiais que emergem compondo sentidos de novo espaço.

Segundo Deleuze e Guattari, 1997, os processos de territorialização não são constitutivos de um sujeito, mas de um estilo. Em certa medida, aposto na existência de uma posição-sujeito artista que produza a marca de uma passagem singular, num movimento do qual emerja uma 'identidade'. No entanto, é factível afirmar também, na arte performática em específico, instalamo-nos em territórios para deles poder fugir, traça-se pontos e linhas de desterritorialização, para que algo ou alguém intervenha sobre o sentido ali instalado, como se o próprio território "tendesse a abrir-se para um futuro, em função das forças em obra que ele abriga" (Deleuze e Guattari, 1997, p.117).

De certa forma, quando Abramovic convida os visitantes da exposição a participar da performance (sugerindo que ocupem a cadeira disposta em frente a ela e compartilhem um tempo indeterminado de silêncio) o espaço recortado do museu cartografa o território pelo modo mesmo como o corpo ali está implicado. O corpo em carne. Mas, além disso, o corpo em arte, o corpo que (se) significa diferentemente neste quadro cênico. O corpo como possibilidade da performance.

Observa-se não o que o corpo da artista 'é', ou o que ele 'é', mas “onde o corpo da artista está", qual território ele ocupa. Ao se colocar numa situação de exposição - estática, sentada em uma cadeira no centro do quadro cênico - a artista não necessariamente mostra seu território naquele momento, mas dá a ver 
um território que se compõe com a performance, com o corpo em performance. É possível detectar, então, quais as formas de expressão que o artista com o seu corpo abre mão. Cartografa-se o território de Abramovic (para depois poder fugir dele!). Ou ainda, cartografa-se o território desse corpo estático, parado, sentado, que podemos também chamar de em corpo-em-arte. Produzindo assim nesse território a potência de sua desconstrução, de sua re-significação.

Nessa direção, a performance "The artist is present", e arte performática em geral, abre espaço para a produção de muitos deslizamentos metafóricos contingenciais. Alguns desses comentários (transcritos abaixo) foram produzidos, durante algum evento científico, em que eu apresenta o vídeo "The artist is present"; outros comentários foram formulados por amigos ao assistem também ao vídeo.

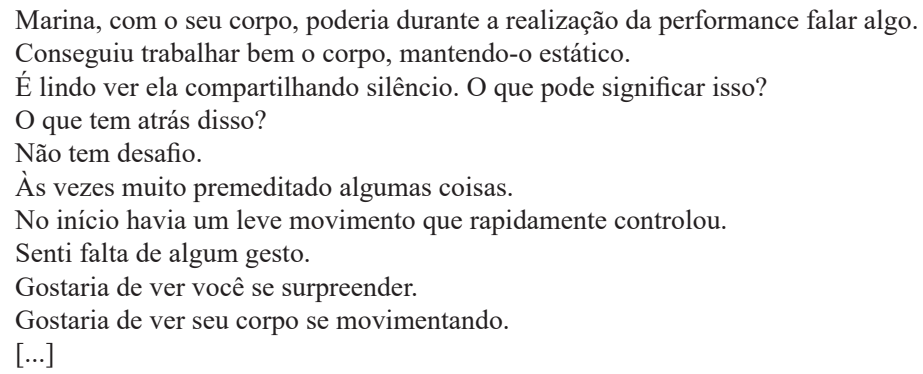

Como se pode perceber, o corpo instalado nesse território abre para um processo de interpretação contingencial, injungindo a um sempre possível processo de desestruturação-restruturação das redes e trajetos de identificação do sujeito com o sentido, vice-e-versa. Isso pois, como formulou Pêcheux (2002):

“[...] só por sua existência, todo discurso marca a possibilidade de uma desestruturaçãoreestruturação dessas redes e trajetos: todo discurso é o índice potencial de uma agitação nas filiações sócio-históricas de identificação, na medida em que ele constitui ao mesmo tempo um efeito dessas filiações e um trabalho (mais ou menos consciente, deliberado, construído ou não, mas de modo atravessado pelas determinações inconscientes) de deslocamento no seu espaço: não há identificação plenamente bem sucedida, isto é, ligação sócio-histórica que não seja afetada, de sua maneira ou de outra, por uma 'infelicidade' no sentido performativo do termo - isto é, no caso, por um 'erro de pessoa', isto é, sobre o outro, objeto da identificação. (PÊCHEUX, 2002, p. 56-57)

Não havendo identificação bem-sucedida sobre esse outro, objeto nosso de identificação, o trabalho da desterritorialização (contida no próprio território) acontece, produzindo um desmanche sutil, de pequenas coisas, do quase imperceptível para o aparecimento do singular de si mesmo. O espaço é deslocado. Para Suely Rolnik (2006; 2012), cartografar um território implica em estar atento às estratégias das formações do desejo em qualquer fenômeno da existência humana, o cartógrafo "deixa o seu corpo vibrar em todas as frequências possíveis e fica inventando posições a partir das quais essas vibrações encontrem sons, canais de 
passagem, carona para a existencialização. Ele aceita a vida e se entrega. De corpo e língua." (Rolnik 2006, p. 66).

Nessa tensão, nesse movimento próprio do território, do espaço cênico recortado, talvez possa se produzir fissuras de respiro. E por essas frestas de ar que o corpo-em-arte re-existe.

\section{Corpo e(m) performance no trabalho da significação}

De que modo o corpo comparece na situação de uma performance? De início, diria: o corpo comparece pela via da fala, mas não me refiro aqui a uma fala do corpo ou sobre o corpo, mas é o corpo enquanto ele fala, corpo que significa. É o corpo do sujeito, da linguagem, constituídos pelo "confronto do simbólico com o político" (Orlandi, 2002, p.91).

Corpo e sujeito, que em performance, se dão enquanto um processo de significação atravessados de memória. Isto quer dizer,

...assim como as palavras já vem significando antes mesmo que as tomemos como nossas palavras, nosso corpo já vem sendo significado mesmo que não o tenhamos, conscientemente, significado. Não há corpo que não esteja investido de sentido, e que não seja o corpo de um sujeito que se constitui por processos de subjetivação nos quais as instituições e suas práticas são fundamentais para a forma com que ele se individualiza, assim como o modo pelo qual, ideologicamente, somos interpelados em sujeitos, enquanto forma histórica.

(ORLANDI, 2002, p.91-92)

Nesse sentido, é possível afirmar que há maneiras e espaços do corpo (se) significar. Numa discursividade sobre o humano, existem historicamente formas e lugares para que o sentido seja possível ao sujeito que interpreta.

Nesse lugar de pensar, a performance é sentido; constitui espaço de interpretação; é um movimento (de significação) que liga (estrutura) corpo, espaço e sujeito; constitui uma forma específica de produção dos sentidos.

Em meio a toda profusão, (des)instalação dos sentidos postos em jogo na produção de um modo de significação, provoca-me o fato de, ao tematizar a performance, a relação entre performance e movimento (de significação) aí insistir. Indício, talvez, de uma especificidade do domínio de significação da performance. Em cena, pensei, temos um corpo (um corpo qualquer?) que forma a base de compreensão de algo cenicamente instalado.

Entre as inúmeras possibilidades de articular corpo/performance interessa lidar com a performance como um espaço de produção e estabilização de sentidos de movimentos, configurando memória (Pêcheux, 1990).

O que proponho é pensar a performance como um, entre outros, espaço discursivo fluido de memória em movimento. Espaço de diferentes movimentos, recortado por esquecimentos, recobrimentos, deslocamentos e tensões de sentidos. Espaço, portanto, que se estrutura entre outras formas, ritualizadas ou não, mas sempre políticas de subjetivação dos sujeitos.

Performance como espaço discursivo, mobiliza, como indiquei, a noção de memória. Para além dos limites entre um espaço subjetivo ao sujeito e uma 
exterioridade, que se elabora, por exemplo, como memória histórica, direi que a memória a qual a performance remete se apresenta "como estruturação da repetição e da regularização" (Pêcheux, 1999, p.52). A repetição, de acordo com Pêcheux, é "um efeito material que funda comutações e variações, e assegura (...) o espaço da estabilidade de uma vulgata parafrástica produzida por recorrência, quer dizer, por repetição literal dessa identidade material” (Pêcheux, 1999, p. 53).

Repetição e regularização dos sentidos como condição de estruturação de um espaço discursivo. É dessa forma que proponho tomar a performance como espaço discursivo fluido de memória do movimento. Tomo como base o que Pêcheux (1999, p., 56) formulou a respeito:

\begin{abstract}
Ser concebida como uma esfera plena, cujas bordas seriam transcendentais históricos e cujo conteúdo seria um sentido homogêneo, acumulado ao modo de um reservatório: é necessariamente um espaço móvel de divisões, de disjunções, de deslocamentos e retomadas, de conflitos de regularização... um espaço de desdobramentos, réplicas, polêmicas e contradiscursos.
\end{abstract}

A repetição formal de um movimento ou gesto no nível da realização (espetáculo) de uma performance - pensando aqui que espetáculo pode ser compreendido como a textualização da performance - é um mecanismo de constituição da performance como memória.

Como formula Orlandi (2004), os espaços são organizados de forma política. Na performance não seria diferente. Enquanto hipótese, infiro que há uma espécie de interconstitutividade entre espaço e corpo.

Nesse trajeto, é possível tomar a performance como um objeto simbólico que inscreve, ou seja, formula sentidos - em seu modo mesmo de ganhar existência na relação contingencial ${ }^{3}$ do sujeito com o Real e também com o real do espaço. A performance é desse modo uma forma de textualização do político, um modo de dar a ver interpretações (jogo forte com a re-divisão de algo do Real).

O gesto de produção de uma performance se dá enquanto necessidade de tornar algo do Real discernível, diria “organizado". A performance se produz, discursivamente, na relação entre o(s) sujeito(s), é linguagem em suas diferentes formas e história. Enquanto especificidade, observo que o corpo do sujeito em performance se diz numa certa relação histórica com múltiplas formas materiais. Entra em cena no átrio do MoMa sujeitos em um estado específico: o da performance. E nesse caso, no modo mesmo como tais corpos em performance se dão a ver, é que penso sujeitos (no plural) instalados (instalando sentidos) em cena.

Parece haver nesse lugar, o da performance, possibilidade "de identificação com outros sentidos que tornam possível ao sujeito fazer sentido, muitas vezes a partir do não-sentido ou da falta de sentido" (Rodrigues, 2011, p.05). É, portanto, nessa medida que a performance trabalha os diferentes modos de significar a relação sujeito-espaço, corpo-espaço. Sua textualidade recorta o movimento

${ }^{3}$ Leio o contingencial aqui como algo que é da ordem do constitutivo, do estruturante dos sentidos. 
aparentemente trivial (de sentar-se em silêncio diante de outra pessoa por um determinado tempo), produzindo o movimento de identificação de sujeitos.

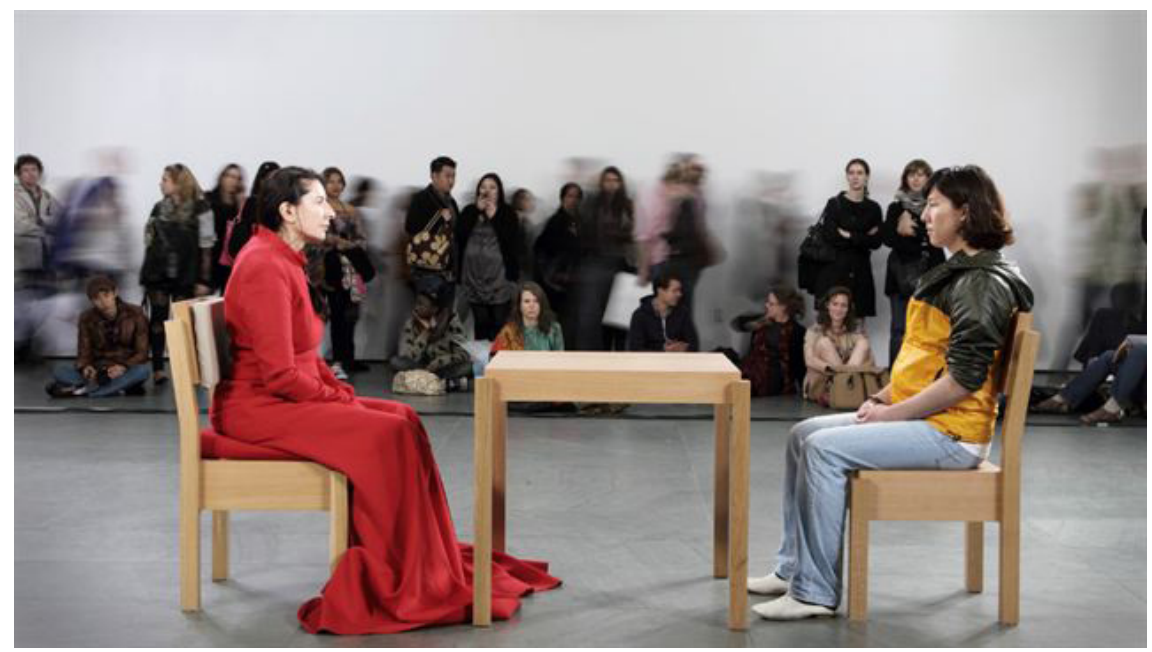

(The Artist Is Present (A artista está presente), 2010)

Ao dispor em cena uma mesa e duas cadeiras e um conjunto de sujeitos identificados com os sentidos que significam "arte", a performance deixa ver que, discursivamente, os sentidos se produzem em várias direções. Deixa instalar o movimento próprio da significação, na história, jogando em cena com os recortes da memória que tornam possíveis outros sentidos.

\section{CONCLUSÃO}

O inusitado dos sentidos, o inusitado do corpo-sujeito em relação a performance acontecendo no espaço de um Museu, o MoMa, não necessariamente se dá enquanto sua característica fundante, nem mesmo o fato da performance acontecer sobre um espaço forjado, o átrio do museu. Esse sempre é e sempre será palco de diversas formas que conformam sentidos de arte.

É nessa medida, aposto, que na performance o trabalho com os sentidos se dá pela via da formulação. E a performance como discurso se textualiza no corpo do sujeito enquanto encadeamento (organização) de múltiplas sequências discursivas.

Desse modo, com Orlandi (2001, p.159), penso:

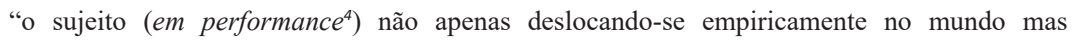
materialmente ( na história e na sociedade) em suas processos de significação/identificação, como sujeitos de sentido.

Na performance temos outas formas (diferentes da dança, da pintura, da pichação, etc....) de atar o corpo do sujeito ao corpo social, uma forma

\footnotetext{
${ }^{4}$ Acréscimo nosso.
} 
singular (Orlandi 2002) na produção de diferentes efeitos de sentido. O corpo como espessura material significante posiciona discursivamente o sujeito, no caso da performance, coloca-o em cena numa sempre relação à produção dos sentidos.

\section{REFERÊNCIAS}

ABRAMOVIC, Marina. Doc. The Artist Is Present, 2010.

BADIOU, Alain. Elogio ao amor; tradução Dorothée de Bruchard - Sâo Paulo: Martins Fontes, 2013.

DELEUZE, Gilles. GUATTARI, Félix. Mil Platôs: capitalismo e esquizofrenia, vol. 4. Trad. Suely Rolnik. São Paulo: Ed.34, 1997.

GOIFMAN, Kiko. Território Vermelho [documentário-vídeo]. Produção de Jurandir Muller, direção de Kiko Goifman, São Paulo, 2004

ORLANDI, Eni Puccinelli. "Sentidos em fuga: efeitos da polissemia e do silêncio". In: Sujeito, sociedade, sentidos. Guilherme Carrozza; Mirian dos Santos; Telma Domingues da Silva. (Orgs.) Campinas: Editora RG, 2012

ORLANDI, Eni Puccinelli. "Textualização do corpo: a escritura de si”. In: Cidade dos Sentidos. Campinas: Pontes, 2004. 159 p.

ORLANDI, Eni Puccinelli. As formas do silêncio: no movimento dos sentidos. 3. ed. Campinas-SP: Editora da UNICAMP, [2007- 1997] 1995-1999.

ORLANDI, Eni Puccinelli. Coreografar: inscrever significativamente o corpo no espaço. In.: Interfaces da dança para pessoas com deficiência/ organizadores: Eliana Lúcia Ferreira, Maria Beatriz Rocha Ferreira, Vera Aparecida Madruga Forti. Campinas: CBDCR, 2002.

ORLANDI, Eni Puccinelli. Dança e Discurso. In.: Anais do I Simpósio Internacional Dança em Cadeira de Rodas; 2001: Campinas, SP UNICAMP, Curitiba: ABRADECAR, 2001.

PÊCHEUX, Michel. O Discurso: estrutura ou acontecimento. Tradução Eni Puccinelli Orlandi. 3. ed. Campinas-SP: Pontes, [1990-2002-2008].

PÊCHEUX, Michel. Delimitações, inversões, deslocamentos. Cad. Est. Ling., Campinas, jul./dez. 1990.

PÊCHEUX, Michel. 1978) Só há causa daquilo que falha ou o inverno político francês: início de uma retificação Em: Pêcheux, M. Semântica e discurso: uma crítica à afirmação do óbvio, Campinas: Ed. Unicamp, [1997-2009].

PÊCHEUX, Michel. Ler o arquivo hoje. In: ORLANDI, E. (Org.). Gestos de leitura: da história no discurso. Campinas, SP: Editora da Unicamp, 1999. (p. 55-64).

PHELAN, Peggy. A ontologia da performance: representação sem reprodução. Revista de Comunicação e Linguagens, Lisboa: Edição Cosmos, n. 24, p.171-191, 1997. 
PLUCHART, François. L’art corporel. Paris: Images 2, 1983.

RODRIGUES, Eduardo Alves. Uma leitura da cena contemporânea: o flashmob como metáfora da relação entre silêncio e linguagem. Seminário de Estudos em Análise do Discurso (5.: 2011: Porto Alegre, RS) Anais do V SEAD - Seminário de Estudos em Análise do Discurso [recurso eletrênico] - Porto Alegre: Instituto de Letras da UFRGS, 2011. Comissão Organizadora do V SEAD: Maria Cristina Leandro Ferreira, Freda Indursky e Solange Mittmann. Organização dos Anais: Solange Mitimann e Dulce Beatriz Mendes Lassen. Disponível em: http//www. analisedodiscurso.ufrgs.br/anaisdosead/sead5.html. ISSN 2237-8146.

ROLNIK, S. Cartografia Sentimental. Porto Alegre: Editora da UFRGS, 2006.

SCHECHNER, Richard. O que é performance? Revista O Percevejo, Tradução Dandara, Rio de Janeiro: UNI-RIO, ano 11, 2003, p.25-50. 